Surveyor

\title{
L.S. Examination Problems
}

\section{H. G. Foxall}

To cite this article: H. G. Foxall (1918) L.S. Examination Problems, Surveyor, 31:6, 195-197, DOI: 10.1080/18324460.1918.10439444

To link to this article: http://dx.doi.org/10.1080/18324460.1918.10439444

曲 Published online: 01 Aug 2012.

Submit your article to this journal

LIII Article views: 3

Q View related articles ¿ 
to reclaim four separate plots aggregating 500,000 acres in extent, and to leave the rest as a fresh water lake to be drawn on for Agricultural purposes. This will be a boon in itself as there is much scarcity of fresh water in Holland in the dry season. The reclaimed land will be fit for occupation in about 20 years. The completion of this great reclamation scheme will be a fitting crown to the steady reclamation policy pursued by the Dutch for centuries, which has in recent years progressed at the rate of 25,000 acres annually. Although Holland will have, by the completion of this project, to sacrifice the valuable fisheries of the Zee, there will be some compensating benefits apart from the main one of giving to the country an enormous accession of fertile land. For one thing, the serious floods that sometimes devastate the country by overflow from the Zee, will no longer recur ; for another, by carrying a railway over the embankment direct communication will be established between Friesland and North Holland.

\section{L.S. Examination Problems.}

The following solutions of problems recently set in the I.S. Examination may be of interest :-

$A B C D$ represents a perfect square of unknown dimensions, $E$ and $F$ on the sides $A D, A B$.

The angle $E C F$ equal to $49^{\circ} 25^{\prime}$, and lengths $C E, C F \quad 2,8 \mathbf{I}^{6} \mathbf{T}^{7} \mathrm{o}$ and $2,75^{\circ}$ links respectively.

Required side of square to nearest link.

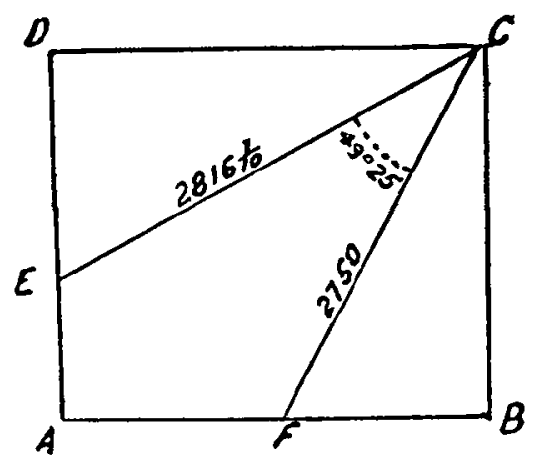

$D C=2816.7 \sin D E C$

$C B=275^{\circ} \sin C F B$

But $D C=C B \therefore \frac{\sin D E C}{\sin C F B}=\frac{2750}{2816.7}$ 


$$
\begin{aligned}
& \begin{aligned}
& D E C+C F B=90^{\prime}-D C E+90^{\circ}-F C B \\
&=180^{\circ}-40^{\circ} 35^{\prime} \\
&=139^{\circ} 25^{\prime} \\
& \text { From (I) and (2) } \frac{\tan (D E C+C F B)}{\tan (D E C-C F B)}=\frac{2750+28 \mathrm{I} 6.7}{2750-2816.7}
\end{aligned}
\end{aligned}
$$

giving $D E C-C F B$, whence $D E C$ and $C F B$.

From either of these angles the side of the square can be computed.

In the figure hereunder $B X C$ is a straight line, and $B Q R=$ $X P R=90^{\circ} ; B X=C P=1,000$ links.

From data given compute the lengths $B Q, C X$, arc $P Q$, angle $P R Q$, and the area $B C P Q$ fronting on arc $P Q$.

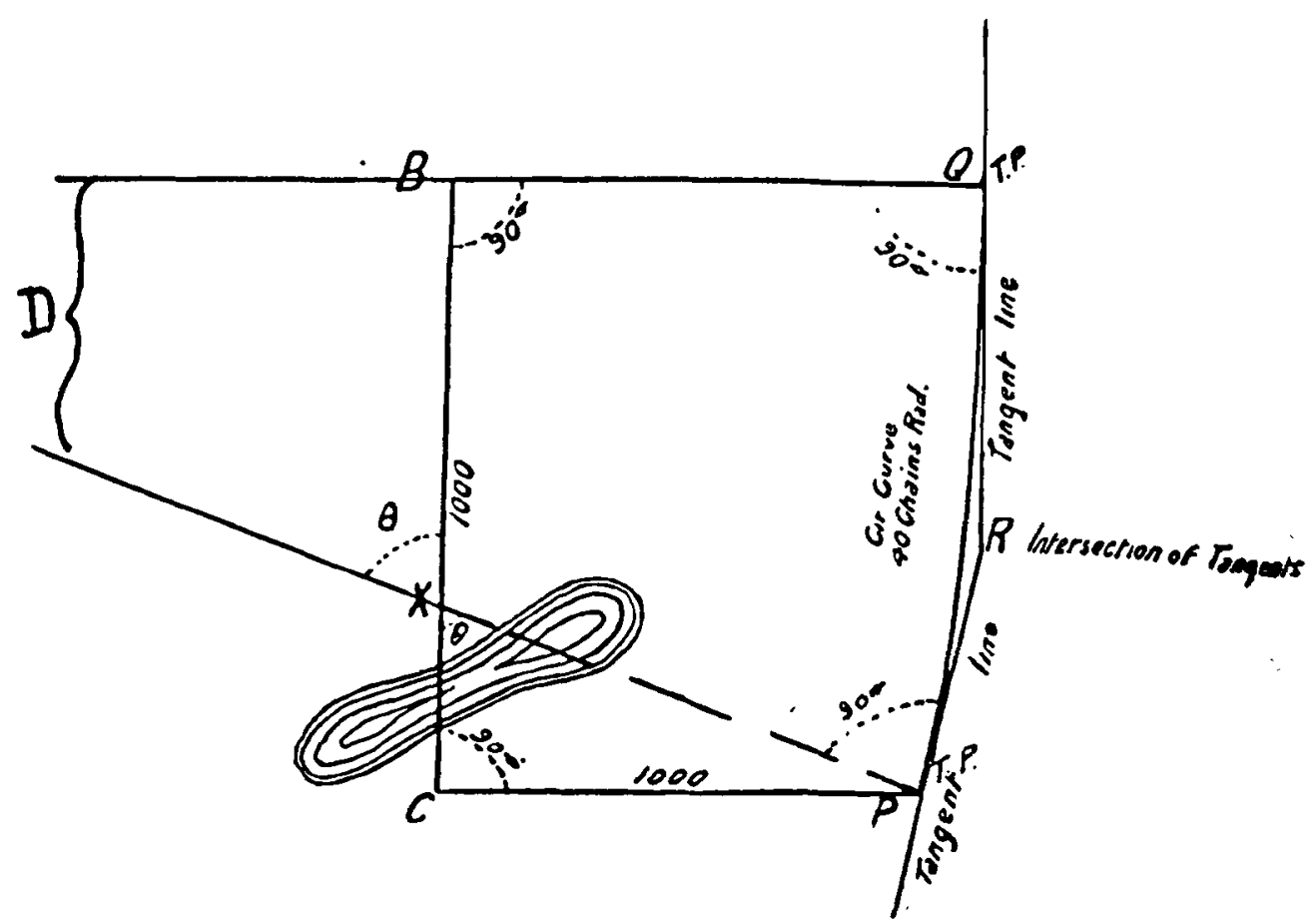

Produce $Q B$ and $P X$ to meet at $D$.

Then $P D=40$ chains.

Let angle $X$ be

$P X=$ ro cosec •

$D X=$ I0 sec

$$
\therefore \frac{10}{\sin \theta}+\frac{10}{\cos \theta}=40
$$

$\cos \theta+\sin \theta=4 \sin \theta \cos \theta$ 
DEC. 3I, 1918.

THE SURVEYOR.

squaring $\cos ^{2} \theta+2 \sin \theta \cos \theta+\sin ^{2} \theta=I 6 \sin ^{2} \theta \cos ^{2} \theta$

$\therefore$ since $\cos ^{2} \theta+\sin ^{2} \theta=I$

and $2 \sin \theta \cos \theta=\sin ^{2} \theta$

I $+\sin 2 \theta=4 \sin 22 \theta$

whence $\sin 2 \theta$ giving $\theta$ whence everything required.

H. G. FOXALL. 